\title{
Inter- and Intraspecific Activities of Compounds Derived from Sex Pheromone Glands of Currant Borer, Synanthedon tipuliformis (Clerck) (Lepidoptera: Sesiidae)
}

\author{
Raimondas Mozūraitis, ${ }^{\mathrm{a}, \mathrm{b}}$, Vidmantas Karalius ${ }^{\mathrm{a}}$, Vincas Būda ${ }^{\mathrm{a}}$, and Anna-Karin \\ Borg-Karlson $^{\mathrm{b}}$ \\ a Laboratory of Chemical and Behavioural Ecology, Institute of Ecology, Vilnius University \\ Akademijos 2, Vilnius LT-2600, Lithuania \\ b Division of Organic Chemistry, Department of Chemistry, Royal Institute of Technology, \\ SE-10044 Stockholm, Sweden. Fax: +4687912333. E-mail: raimis@kth.se \\ * Author for correspondence and reprint requests \\ Z. Naturforsch. 61c, 278-284 (2006); received October 12/November 3, 2005
}

Gas chromatography and mass spectrometry analyses of crude sex pheromone gland extracts revealed that virgin Synanthedon tipuliformis (Clerck), currant borer (Lepidoptera: Sesiidae) females, produced 6 compounds, structurally related to sex pheromone components of clearwing moths. By comparison of retention times and mass spectra of natural products with corresponding properties of synthetic standards, these compounds were identified as: (2E,13Z)-octadeca-2,13-dien-1-yl acetate (E2,Z13-18:OAc), (3E,13Z)-octadeca-3,13-dien-1-yl acetate $(E 3, Z 13-18$ :OAc), (13Z)-octadec-13-en-1-yl acetate (Z13-18:OAc), (2E,13Z)-octadeca-2,13-dien-1-ol (E2,Z13-18:OH), (13Z)-octadec-13-en-1-ol (Z13-18:OH) and octadecan1-ol (18:OH) in the ratio 100:0.7:2.7:3.2:traces:traces. The first 3 compounds were previously known to occur in the sex pheromone gland extracts of currant borers, while the last 3 chemicals are now reported for the first time. Trapping tests carried out in the black currant field revealed that E2,Z13-18:OAc, when tested separately, attracted S. tipuliformis males, while addition of E3,Z13-18:OAc to the main component increased the effectiveness of $E 2, Z 13-18: O A c$ over seven times. The attractiveness of 6 component lures did not differ significantly from the one of the binary mixture, confirming that E2,Z13-18:OAc and E3,Z1318:OAc in the ratio100:0.7 are essential sex pheromone components of S. tipuliformis. Trapping tests carried out at the dwelling place of Synanthedon scoliaeformis (Borkhausen) (Lepidoptera: Sesiidae) revealed that, in addition to intraspecific synergistic effect, E3,Z13-18:OAc increased the specificity of the pheromone signal of $S$. tipuliformis, acting by intraspecific mode as an attraction antagonist against $S$. scoliaeformis males. By this way, it ensured the specificity of the sex attraction signal of the currant borer. Consequently, both compounds $E 2, Z 13-18$ :OAc and E3,Z13-18:OAc have to be present in pheromone formulations used for monitoring and/or control of S. tipuliformis to avoid effecting non-target species. Other compounds identified from the sex pheromone gland of S. tipuliformis did not show any significant interspecific activity for males of $S$. scoliaeformis, however, they provide a basis to achieve specificity of a pheromone signal of $S$. tipuliformis and could act as attraction antagonists against other clearwing moth species which, like S. tipuliformis, employ E2,Z1318:OAc as their sex pheromone component.

Key words: Pheromone Specificity, Synergist, Attraction Antagonist

\section{Introduction}

The currant borer, Synanthedon tipuliformis (Clerck) (Lepidoptera: Sesiidae) is one of the most destructive pests of the cultivated currants Ribes nigrum L. and R. rubrum L., and gooseberries, Grossularia urva-crispa (L.), in Eurasia (Manko, 1965; Yakimova, 1968; Yonghe et al., 1990; Szốcs et al., 1991; Būda, 1993; Gottwald and Künzel, 1994; Karalius et al., 2003), in North America (Solomon and Dix, 1979; Szốcs et al., 1998), and in Australia (Scott and Harrison, 1978;
Hardy, 1981). S. tipuliformis has one generation per year. In Lithuania, adults emerge in June. Females lay eggs on branches especially near bark wounds. About 2 weeks after hatching, caterpillars bore into the branches and develop on the starchrich pits of currant branches. Larvae of the last stages gnaw out wide tunnels, create large pupation cells and make exit holes for emerging adults, in consequence causing the breaking of currant branches during mechanical harvesting (Hardy, 1981). In addition, microscopic fungi infest 
branches through the exit holes and cause weakening of limbs. Reduced numbers of racemes per branch, fewer flowers per raceme and worse nutrition supplies lead to significant decreases of the yields of berries (Brock et al., 1964; Hardy, 1981; Vazyulya, 1982).

Biological features and life style make this pest difficult to control. The efficacy of chemical pesticides is limited by the short period when the larvae are not protected within the canes and this period often coincides with the harvest period, when pesticide use is prohibited (Grassi et al., 2002). Pheromone use as an alternative control method has been applied for monitoring and mating disruption of S. tipuliformis (Carde and Minks, 1995; Grassi et al., 2002).

The sex pheromone of this moth has been identified as a two-component mixture, consisting of $(2 E, 13 Z)$-octadeca-2,13-dien-1-yl acetate $(E 2$, Z13-18:OAc) as a major component (Szócs et al., $1985)$ and $(3 E, 13 Z)$-octadeca-3,13-dien-1-yl acetate $(E 3, Z 13-18: O A c)$ as a minor constituent (James et al., 2001; Suckling et al., 2005). Our preliminary data indicated the presence of additional compounds, structurally related to sex pheromone components of the Sesiidae, in the extract obtained from pheromone glands of S. tipuliformis females.

The aim of this study was to determine intraand interspecific activities of the compounds identified from sex pheromone glands of S. tipuliformis females.

\section{Materials and Methods}

\section{Insects}

Black currant branches containing S. tipuliformis pupae were collected at Vilnius University Botanical Garden, Kairenai near Vilnius (East Lithuania) at the end of May 2000. The branches had been cut into pieces and the parts containing pupae had been transported to the laboratory and placed in glass containers. The temperature regime for the rearing was $(22 \pm 2)^{\circ} \mathrm{C}$ during the light part of the day and $(18 \pm 2)^{\circ} \mathrm{C}$ during the night, with the $17 \mathrm{~h}: 7 \mathrm{~h}$ light/dark natural photoperiod. The glass containers were inspected every morning and emerged unmated adults were sexed, as it was known that high sex pheromone release activity of S. tipuliformis females started about $8 \mathrm{~h}$ before sunset (Būda and Karalius, 1985). Virgin females were transferred to holding containers containing a solution of $5 \%$ honey in water. In addition to moths obtained from the pupae, a number of females were collected by an entomological net in the same black currant plantation during the second half of June.

\section{Extraction of the sex pheromone glands}

When the female was found calling, her abdominal tip containing the sex pheromone gland was pushed out under mechanical pressure, excised and washed twice with $10 \mu \mathrm{l}$ of hexane (Merck, p.a.) for $15 \mathrm{~min}$. The solution was removed, concentrated to approx. $10 \mu \mathrm{l}$, and stored at $-14{ }^{\circ} \mathrm{C}$. In total, 12 calling females were used for this extraction.

\section{Chemical analyses}

The extract was analyzed by using the Finnigan SSQ 7000 GC-MS system, including a Varian 3400 GC instrument. Both DB-5 and DB-wax silica capillary columns ( $\mathrm{J}$ and W Scientific, Folsom, CA, USA, $30 \mathrm{~m}, 0.25 \mathrm{~mm}$ i.d., film thickness $0.25 \mu \mathrm{m}$ ) were used with a temperature program of $80^{\circ} \mathrm{C}$ (4 min), increased by $10^{\circ} \mathrm{C} / \mathrm{min}$ to $170{ }^{\circ} \mathrm{C}$, then by $2{ }^{\circ} \mathrm{C} / \mathrm{min}$ up to $210^{\circ} \mathrm{C}$ and thereafter held isothermally at $210^{\circ} \mathrm{C}$ for $30 \mathrm{~min}$. The split/splitless injector temperature was $225{ }^{\circ} \mathrm{C}$ and the splitless period was $30 \mathrm{~s}$. Helium was used as the carrier gas, with an inlet pressure of 10 psi. Electron ionization mass spectra were determined at $70 \mathrm{eV}$ with the ion source at $150{ }^{\circ} \mathrm{C}$. Mass chromatograms obtained from the sex pheromone gland extract were screened for compounds structurally related to the sex pheromone components, using diagnostic ions $\mathrm{m} / \mathrm{z} 61$ (protonated acetic acid, indicating presence of acetates), $\mathrm{m} / \mathrm{z} 248, \mathrm{~m} / \mathrm{z} 250$ and $\mathrm{m} / \mathrm{z}, 252$ $\left(\left[\mathrm{M}^{+} \cdot-18\right]\right.$, loss of water for octadecadienols, octadecenols and octadecanols, respectively, as well as $\left[\mathrm{M}^{+\cdot}-60\right]$, loss of acetic acid for octadecadien-1-yl acetates, octadecen-1-yl acetates and octadecan-1$\mathrm{yl}$ acetates, respectively). The compounds selected for analyses were identified by comparison of their mass spectral data and GC-retention times with the corresponding data from synthetic standards.

\section{Chemicals}

The synthetic compounds to be used as GC-MS standards had been obtained from Pherobank, (Wageningen, Netherlands) as well as from Flora Co. (Tartu, Estonia). The chemicals used in the 
field tests had been synthesized in Tartu, Estonia, and purified by preparative liquid chromatography, as described by Mozūraitis et al. (1998). The isomeric and chemical purities of the compounds exceeded $99 \%$.

\section{Field tests}

The synthetic sex pheromone components were dissolved in hexane (Merck, p.a.) and soaked from the inside into the walls of red rubber tube dispensers $(8 \times 15 \mathrm{~mm})$. The compounds were applied either alone or in mixtures, as indicated in Tables I and II. Each lure was placed in an opaque white delta trap (trapping window sides $10 \mathrm{~cm} \times 11 \mathrm{~cm}$ $\times 10 \mathrm{~cm}$ and trap length $18 \mathrm{~cm}$ ), which had an exchangeable bottom $(11 \mathrm{~cm} \times 18 \mathrm{~cm})$, coated with sticky material. "Atracon A" traps and Pestifix glue were obtained from Flora Co., Tartu, Estonia.) Tests of the attractiveness of synthetic compounds, identified from sex pheromone gland extracts of S.tipuliformis females, to conspecific males were carried out in the black currant plantation at Vilnius University Botanical Garden, Kairènai near Vilnius (East Lithuania) from June 1 to 29, 2001. Each trap was fixed on a black currant branch at $3 / 4$ of the shrub height, which is the optimal position for achieving the most abundant catches (Būda and Karalius, 1993), and was inspected and moved to the next trap location (within each replication) every $3 \mathrm{~d}$. The distance between the traps was at least $15 \mathrm{~m}$. Five replicates of each compound and mixture listed in Table I were used.

Bioactivity tests of synthetic compounds identified from sex pheromone gland extracts of S. tipuliformis females toward S. scoliaeformis males were conducted at the edge of a deciduous forest with birch trees dominant in Visoriai and Žemaitèliai near Vilnius (East Lithuania). Traps were fixed on branches of the shrubs growing close to birch trees about $2 \mathrm{~m}$ above ground and were inspected and moved to the next trap location (within each replication) every $3 \mathrm{~d}$. The distance between the traps was at least $15 \mathrm{~m}$. Five replicates of each compound and mixture listed in Table II were used.

\section{Identification of moth species}

The moths captured were identified through their external morphological characters. Representative specimens were deposited in the insect collection at the Institute of Ecology, Vilnius, Lithuania.

\section{Statistical analyses}

Data from the field tests were analyzed by nonparametric Kruskal-Wallis (Sokal and Rohlf, 1995) analyses of variance, followed by Mann-Whitney U-test (Sokal and Rohlf, 1995) and significantly different catches were marked with different letters at $P<0.05$.

\section{Results}

\section{Chemical analysis of the sex pheromone glands} extract

Six compounds structurally related to sex pheromone components of clearwing moths were detected from sex pheromone gland extracts of virgin females, when GC-MS data were screened by diagnostic ions.

Compounds II and IV (Fig. 1A) showed a clear presence of the diagnostic ions $\mathrm{m} / \mathrm{z}, 248$ and $\mathrm{m} / \mathrm{z}$ 61, typical of octadecadien-1-yl acetates (Fig. 1B). Comparison of the retention times of natural products and synthetic standards on two capillary columns of different polarities revealed compound II as $(3 E, 13 Z)$-octadeca-3,13-dien-1-yl acetate $(E 3$, $Z 13-18: O A c)$ and compound IV as $(2 E, 13 Z)$ octadeca-2,13-dien-1-yl acetate (E2,Z13-18:OAc). Fragmentation patterns of mass spectra of $E 3, Z 13$ 18:OAc and E2,Z13-18:OAc, recorded from the extracts, corresponded well to the ones of synthetic standards.

Compound VI showed a mass spectrum that was very similar to those of II and IV. The complete absence of diagnostic ions at $m / z 61$ (Fig. 1B) suggested that compound VI was octadecadienol. Synthetic (2E,13Z)-octadeca-2,13-dien-1-ol (E2,Z13$18: \mathrm{OH})$ had the same retention time as compound VI and the two compounds showed identical mass spectra.

The occurrence of diagnostic ions at $\mathrm{m} / \mathrm{z}, 250$ in mass spectra obtained from compounds I and V as well as the presence of $m / z, 61$ only in the mass spectrum of compound I indicated that the natural products I and V were octadecen-1-yl acetate and octadecenol, respectively (Fig. 1B). The stereochemistry and the position of the double bond in both compounds were determined as Z13-, by comparison of retention times of natural products and corresponding characteristics of synthetic 
A

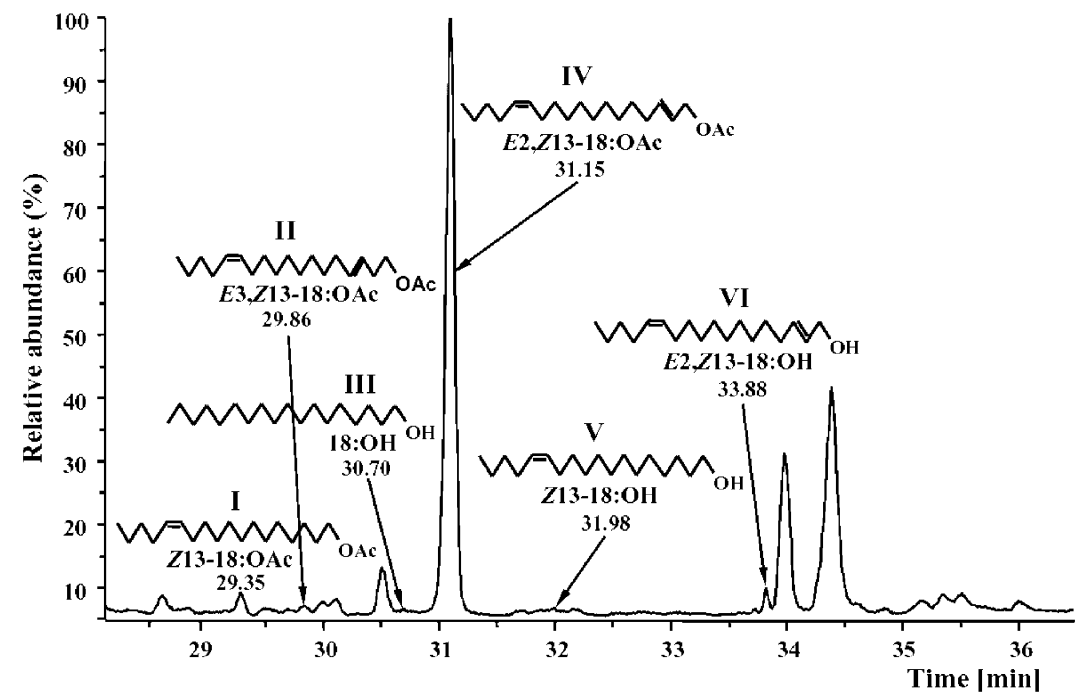

B

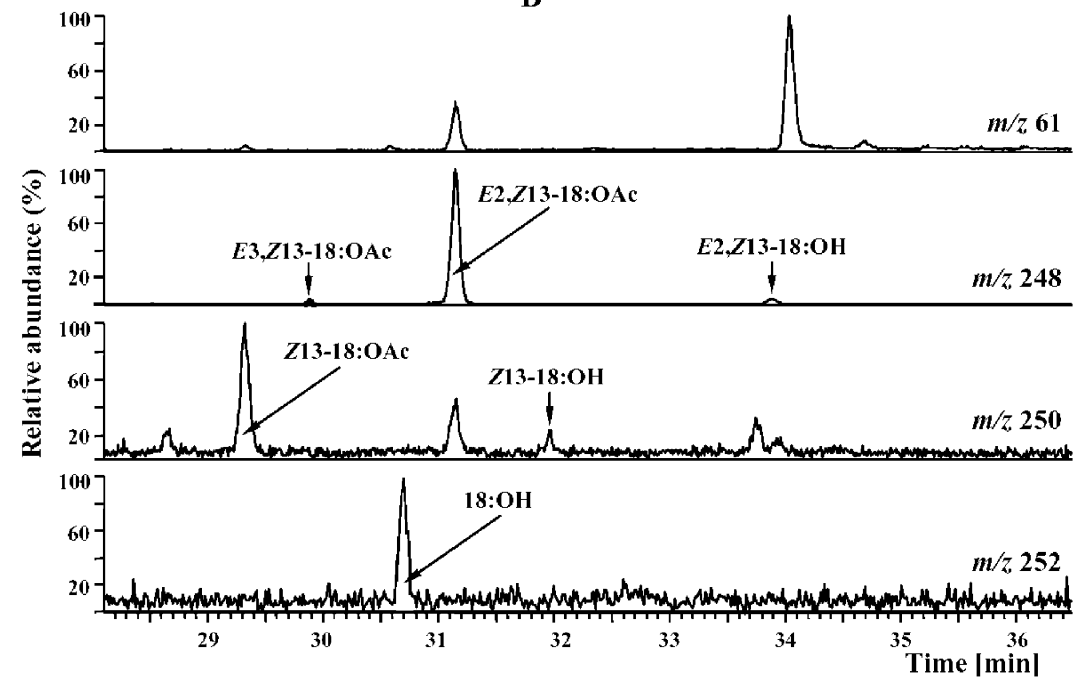

Fig. 1. Total and selected ion chromatogram records of extracts obtained from 6 virgin calling Synanthedon tipuliformis females. (A) Total ion chromatogram in the range $\mathrm{m} / \mathrm{z}, 30-400$; polar DB-Wax fused silica capillary column $(30 \mathrm{~m}$ $\times 0.25 \mathrm{~mm}$ i.d., $0.25 \mu \mathrm{m}$ film thickness). (B) Selected ion chromatograms, with $m / z 61$ ion fragments indicating the presence of acetates; $\mathrm{m} / \mathrm{z}, 248, \mathrm{~m} / \mathrm{z} 250$ and $\mathrm{m} / \mathrm{z}$ 252 are the molecular ions characteristic of octadecadienols, octadecenols, octadecanols and their acetates, respectively. standards, indicating that compounds I and $\mathrm{V}$ were (13Z)-octadec-13-en-1-yl acetate (Z13-18:OAc) and (13Z)-octadec-13-en-1-ol (Z13-18:OH), respectively.

Compound III showed a mass spectrum that was very similar to that of octadecan-1-ol $(18: \mathrm{OH})$, presented by the Mass Spectral Library, version 1.7 of National Institute of Standard and Technology, USA. Comparisons of the mass spectra and retention times of the natural product and the ones of the synthetic standard confirmed that compound III was octadecan-1-ol.

In conclusion, E2,Z13-18:OAc, E3,Z13-18:OAc, Z13-18:OAc, E2,Z13-18:OH, Z13-18:OH and 18:
$\mathrm{OH}$ in the ratio 100:0.7:2.7:3.2:traces:traces were determined from the sex pheromone gland extracts of 6 females.

\section{Field trapping}

Bioassay tests of synthetic compounds, identified from sex pheromone gland extracts of virgin S. tipuliformis females, revealed that only the main component E2,Z13-18:OAc was attractive to conspecific males, when two sex pheromone components were tested alone under field conditions (Table I). Addition of E3,Z13-18:OAc to the main component increased the effectiveness of E2,Z13- 
Table I. Attraction of Synanthedon tipuliformis and S. scoliaeformis males in a black currant plantation to synthetic compounds identified from sex pheromone gland extracts of S. tipuliformis females.

\begin{tabular}{lccc}
\hline Compound & Amount & \multicolumn{2}{c}{ Males per trap (mean $\pm \mathrm{SD})$} \\
\cline { 3 - 4 } & {$[\mu \mathrm{g}]$} & S. tipuliformis & $S$. scoliaeformis \\
\hline E2,Z13-18:OAc & 280 & $2.8 \pm 1.5 \mathrm{~b}$ & $1.6 \pm 1.1 \mathrm{a}$ \\
$E 3, Z 13-18:$ OAc & 2.3 & $0 \pm 0$ & $0 \pm 0$ \\
$E 2, Z 13-18: O A c+E 3, Z 13-18: O A c$ & $280+2.3$ & $20.8 \pm 7.3 \mathrm{a}$ & $0.6 \pm 0.9 \mathrm{ab}$ \\
Identified mixture & 300 & $19.6 \pm 5.5 \mathrm{a}$ & $0 \pm 0$ \\
Control & - & $0 \pm 0$ & $0 \pm 0$ \\
\hline
\end{tabular}

Identified mixture corresponds to E2,Z13-18:OAc $280 \mu \mathrm{g}+E 2, Z 13-18: O H 9 \mu \mathrm{g}+Z$ Z13-18:OAc 8.5 $\mu \mathrm{g}+$ E3,Z1318:OAc $2.3 \mu \mathrm{g}+Z 13-18: \mathrm{OH} 0.1 \mu \mathrm{g}+18: \mathrm{OH} 0.1 \mu \mathrm{g}$; control represents dispensers loaded with solvent only; SD denotes standard deviation; 5 replicates; the differences between numbers followed by different letters are statistically significant at $P<0.05$ according to nonparametric Kruskal-Wallis analyses of variance, followed by MannWhitney U-test.

Table II. Attraction of Synanthedon scoliaeformis males under field bioassay to synthetic compounds identified from sex pheromone gland extracts of S. tipuliformis females.

\begin{tabular}{lcc}
\hline Compound & Amount & Males per trap (mean $\pm \mathrm{SD})$ \\
\cline { 2 - 3 } & {$[\mu \mathrm{g}]$} & S. scoliaeformis \\
\hline$E 2, Z 13-18: O A c$ & 280 & $3.4 \pm 1.9 \mathrm{a}$ \\
$E 2, Z 13-18:$ OAc $+E 2, Z 13-18: O H$ & $280+9$ & $5.0 \pm 1.5 \mathrm{a}$ \\
$E 2, Z 13-18:$ OAc $+E 3, Z 13-18: O A c$ & $280+2.3$ & $0 \pm 0$ \\
$E 2, Z 13-18:$ OAc $+Z 13-18: O A c$ & $280+8.5$ & $4.2 \pm 1.8 \mathrm{a}$ \\
$E 2, Z 13-18:$ OAc $+Z 13-18: O H$ & $280+0.1$ & $5.1 \pm 2.1 \mathrm{a}$ \\
$E 2, Z 13-18:$ OAc $+18: O H$ & $280+0.1$ & $4.7 \pm 2.2 \mathrm{a}$ \\
Identified mixture & 300 & $0 \pm 0$ \\
Control & - & $0 \pm 0$ \\
\hline
\end{tabular}

Identified mixture corresponds to 2 E2,Z13-18:OAc $280 \mu \mathrm{g}+E 2, Z 13-18: \mathrm{OH} 9 \mu \mathrm{g}+Z 13-18: \mathrm{OAc} 8.5 \mu \mathrm{g}+E 3, Z 13-$ 18:OAc $2.3 \mu \mathrm{g}+Z 13-18: \mathrm{OH} 0.1 \mu \mathrm{g}+18: \mathrm{OH} 0.1 \mu \mathrm{g}$; control represents dispensers loaded with solvent only; SD denotes standard deviation; 5 replicates; the differences between numbers followed by different letters are statistically significant at $P<0.05$ according to nonparametric Kruskal-Wallis analyses of variance, followed by MannWhitney U-test.

18:OAc over seven times. The attractiveness of six component lures did not differ significantly from the one of the binary lures. In conclusion, E3,Z1318:OAc was the synergist of E2,Z13-18:OAc and these two acetates in the ratio 0.7:100 were essential sex pheromone components of S. tipuliformis.

E2,Z13-18:OAc, tested alone, was also attractive to the males of another Synanthedon species, $S$. scoliaeformis. The presence of E3,Z13-18:OAc in the binary mixture with E2,Z13-18:OAc suppressed the attraction of $S$. scoliaeformis males 2.5 times. However, due to small catches of moths in the black currant field, the antagonistic effect was not statistically significant (Table I).

The trapping tests, carried out at the dwelling place of S. scoliaeformis, revealed that E3,Z1318:OAc, when present in the binary mixture with E2,Z13-18:OAc, suppressed the attractiveness of the latter acetate entirely (Table II). Other compounds identified from sex pheromone glands of S. tipuliformis did not have a significant effect on the attraction of $S$. scoliaeformis males.

Thus, in addition to the intraspecific synergistic effect, E3,Z13-18:OAc increased the specificity of the pheromone signal for S. tipuliformis, when acting by interspecific way as an attraction antagonist to $S$. scoliaeformis males.

\section{Discussion}

GC-MS analyses of crude pheromone gland extracts demonstrated that virgin S. tipuliformis females produced E2,Z13-18:OAc, E3,Z1318:OAc, Z13-18:OAc, E2,Z13-18:OH, Z13-18:OH and $18: \mathrm{OH}$ in the ratio 100:0.7:2.7:3.2:traces:traces. The first 3 compounds were previously known to 
occur in the sex pheromone gland extracts, while the last 3 chemicals were reported for the first time.

The attractiveness of E2,Z13-18:OAc to S. tipuliformis males was discovered by Voerman et al. (1984). Two years later, Priesner et al. (1986) reported, that the attractiveness of E2,Z13-18:OAc was significantly enhanced by the positional isomer E3,Z13-18:OAc, when they were tested together at the ratios 100:3 and 100:10. Later research on synergistic effects of E3,Z13-18:OAc revealed that two strains of currant borers exist according to the response of males to a two-component attractant. Males of the first strain occurring only in Tasmania were clearly attracted to E2,Z13-18:OAc as a single compound (Szőcs et al., 1990; Suckling et al., 2005), whereas males of the second strain significantly preferred a two-component blend, consisting of E2,Z13-18:OAc and 3\% $E 3, Z 13-18$ :OAc. The second strain was found in Europe (Voerman et al., 1984; Szőcs et al., 1990, 1991), New Zealand (Sző́cs et al., 1990) and North America (Szócs et al., 1998). Our trapping data confirmed the synergistic effect of E3,Z13-18:OAc on E2,Z13-18:OAc which was expected to occur for the European population of currant borers.

Shortly thereafter the sex attractant was reported: two compounds, E2,Z13-18:OAc and Z1318:OAc in the ratio 97:3, were identified from sex pheromone gland extracts by Szócs et al. (1985) and only the dienic acetate was confirmed as the sex pheromone. A minor sex pheromone component, E3,Z13-18:OAc, in trace amounts, was detected by means of the GC-EAG method from sex pheromone gland extracts of single females (James et al., 2001). Suckling et al. (2005) have demonstrated that in New Zealand sex pheromone components occurred at the ratio 97:3. We have found that in sex pheromone gland extracts, obtained from currant borer females of Lithuanian population, E2,Z13-18:OAc and E3,Z13-18:OAc were present in the ratio 100:0.7 which is somewhat higher than 100:3 that was used in the optimized lures reported by Szőcs et al. (1990) and identified from sex pheromone gland extracts of New Zealand population (Suckling et al., 2005).

The compositions of sex pheromones and attractants among Sesiidae are highly conserved as, to date, the $E, Z$ - and $Z, Z$-isomers of 3,13- and 2,13octadecadienols, the corresponding acetates and $(2 E, 13 Z)$-octadeca-2,13-dienal are used in sexual communication by clearwing species [http:// www.pherobase.com, an updated website based on the book of Arn et al. (1992)]. Consequently, numbers of Sesiidae species use the same compound as the main sex attractant component, and the specificity of a sex attraction signal could be achieved due to minor components with inter- or/ and intraspecific activity. Būda et al. (1993) demonstrated that two related Synanthedon species, S. tipuliformis and S. scoliaeformis, used E2,Z1318:OAc as their main attractant component. Our data revealed that E3,Z13-18:OAc showed a dual behavioural activity, by synergising attractiveness of E2,Z13-18:OAc to S. tipuliformis males, and acting as an attraction antagonist to males of the $S$. scoliaeformis species, by this way ensuring the specificity of the sex attraction signal of the currant borer.

In addition to the sex pheromone compounds of S. tipuliformis, another 4 chemicals E2,Z1318:OH, Z13-18:OAc, Z13-18:OH and 18:OH, identified from the sex pheromone glands, did not show any biological activity, neither to S. tipuliformis nor to S. scoliaeformis males. However, they provide a basis to achieve specificity of a pheromone signal of S. tipuliformis and could act as attraction antagonists against other clearwing moth species which, like S. tipuliformis, employ E2,Z13-18:OAc as their sex pheromone component. Some of these compounds could be intermediates or side products in biosynthesis of a sex pheromone as well.

It is known that moths from one and seven species of the families Cossidae and Sesiidae, respectively, were attracted to single E2,Z13-18:OAc (based on http://www.pherobase.com). Consequently, the two compounds E2,Z13-18:OAc and E3,Z13-18:OAc have to be present in pheromone formulations used either for monitoring or for control of S. tipuliformis to avoid effects on nontarget species.

\section{Acknowledgements}

This study was supported by state grants to the Laboratory of Chemical and Behavioural Ecology at the Institute of Ecology, Vilnius University, Lithuania, by the New Visby programme sponsored by the Swedish Institute and by the Carl Trygger Fund, Sweden. We thank Dr. G. AulinErdtman for valuable discussions of the manuscript. 
Arn H., Tóth M., and Priesner E. (1992), List of Sex Pheromones of Lepidoptera and Related Attractants, 2nd ed. International Organization for Biological Control, Montfavet, France.

Brock A. M., Collingwood C. A., and White J. M., (1964), The currant clearwing moth Aegeria tipuliformis (Cl.) as a pest of blackcurrants. Ann. Appl. Biol. 53, 243349.

Būda V. (1993), Currant borer, Synanthedon tipuliformis Cl. (Lepidoptera, Sesiidae) in Lithuania. Acta Entomol. Litu. 11, 131-136.

Būda V. and Karalius V. (1985), Calling behavior of females of currant clearwing moth, Synanthedon tipuliformis (Clerck) (Lepidoptera, Sesiidae). J. Appl. Entomol. 100, 297-302.

Būda V. and Karalius V. (1993), Chemical communication in the clearwing Synanthedon tipuliformis $\mathrm{Cl}$. (Lepidoptera: Sesiidae) and its modulation by visual input. In: Sensory Systems of Arthropods (Wiese K., ed.). Birkhäuser Verlag, Basel, Switzerland, pp. 441447.

Būda V., Maeorg U., Karalius V., Rothschild G. H. L., Kolonistova S., Ivinskis P., and Mozuraitis R. (1993), C18 dienes as attractants for 18 clearwing (Sesiidae), tineid (Tineidae), and choreutid (Choreutidae) moth species. J. Chem. Ecol. 19, 799-813.

Carde R. T. and Minks A. K. (1995), Control of moth pests by mating disruption. Annu. Rev. Entomol. 40, $559-585$.

Gottwald R. and Künzel K. (1994), Neue Erkenntnisse zur Populationsökologie des Johannisbeerglasflüglers (Synanthedon tipuliformis Clerck). Gesunde Pflanz. 46, $131-136$.

Grassi A., Zini M., and Forno F. (2002), Mating disruption field trials to control the currant clearwing moth, Synanthedon tipuliformis: a three-year study. IOBC WPRS Bulletin 25, 69-76.

Hardy R. J. (1981), Field observations on the effect of currant borer moth, Synanthedon tipuliformis (Clerck) (Lepidoptera: Aegeriidae), on the yield of blackcurrants produced in Tasmania. Sci. Hortic. 15, $165-172$.

James D. G., Cosse A., Wright L. C., and Perez J. (2001), Pheromone trapping of Synanthedon tipuliformis (Lepidoptera: Sesiidae) in Washington red currants. Environ. Entomol. 30, 663-666.

Karalius V., Būda V., and Mozūraitis R. (2003), Monitoring of the currant clearwing (Synanthedon tipuliformis Cl.) (Lepidoptera, Sesiidae) by pheromone traps in Lithuania. Acta Zool. Litu. 13, 283-289.

Manko V. V. (1965), On biology of currant clearwing moth under Byelorussian conditions. Vestsi Akademyi Navuk Byeloruskoi SSR, Selskie Navuki 4, 70-76 (in Byelorussian).

Mozūraitis R., Būda V., Borg-Karlson A. K., Ivinskis P., Karalius V., Laanmaa M., and Plepys D. (1998), New sex attractants and inhibitors for 17 moth species from the families Gracillariidae, Tortricidae, Yponomeuti- dae, Oecophoridae, Pyralidae and Gelechiidae. J. Appl. Entomol. 122, 441-452.

Priesner E., Dobler G., and Voerman S. (1986), Synergism of positional isomers in sex attractant systems of clearwing moths (Sesiidae). Entomol. Exp. Appl. 41, $311-313$.

Scott R.R. and Harrison R.A. (1978), Sampling plan for population dynamics studies on currant clearwing, Synanthedon tipuliformis (Lepidoptera: Sesiidae). N. Z. J. Zool. 5, 177-184.

Sokal R. R. and Rohlf F. J. (1995), Biometry. Freeman and Co, New York, USA.

Solomon G. D. and Dix E. M. (1979), Selected bibliography of the clearwing borers (Sesiidae) of the United States and Canada. US Forest Service General Technical Report SO-22, USA.

Suckling D. M., Gibb A. R., Burnip G. M., Snelling C., De Ruiter J., Langford G., and El-Sayed A. M. (2005), Optimization of pheromone lure and trap characteristics for currant clearwing, Synanthedon tipuliformis. J. Chem. Ecol. 31, 393-406.

Szőcs G., Schwarz M., Sziraki G., Toth M., Klun J. A., and Leonhardt B. A. (1985), Sex pheromone of the female currant borer, Synanthedon tipuliformis: identification and field evaluation. Entomol. Exp. Appl. 39, $131-133$.

Szőcs G., Miller L. A., Thomas W., Vickers R. A., Rothschild G. H. L., Schwarz M., and Toth M. (1990), Compounds modifying male responsiveness to main female sex pheromone component of the currant borer, Synanthedon tipuliformis Clerk (Lepidoptera, Sesiidae) under field conditions. J. Chem. Ecol. 16, 1289-1305.

Szőcs G., Būda V., Charmillot P., Esbjerg P., Freier B., Gottwald R., Kovalev B., Maini S., Solomon M. G., Sorum O., Subchev M., Tóth M., and Van de Veire M. (1991), Field tests of (E,Z)-3,13-octadecadien-1-ol acetate: a sex attractant synergist for male currant borer, Synanthedon tipuliformis. Entomol. Exp. Appl. 60, 283-288.

Szócs G., Henderson D., and McNeil J. N. (1998), Old World pheromone strain in the New World: sex attractant composition for the currant borer, Synanthedon tipuliformis Cl. (Lepidoptera: Sesiidae) in Canada. Can. Entomol. 130, 231-234.

Vazyulya A. G. (1982), Pest and diseases of black currant. Zashchita Rastenii. 7, 54-55 (in Russian).

Voerman S., Persoons C. J., and Priesner E. (1984), Sex attractant for currant clearwing moth Synanthedon tipuliformis (Clerck) (Lepidoptera, Sesiidae). J. Chem. Ecol. 10, 1371-1376.

Yakimova N. L. (1968), Some factors influencing the population dynamics of Synanthedon tipuliformis $\mathrm{Cl}$. (Lepidoptera, Aegeriidae). Entomol. Rev. 47, 19-30 (in Russian).

Yonghe Z., Ruxian B., Wendong L., and Xin Z. (1990), The occurrence of Synanthedon tipuliformis (Clerck) and its control. Insect Knowledge 27, 148-149. 